\title{
Effect of Irisin on LIF and integrin av $\beta 3$ in rats of implantation failure
}

\author{
Li Zhou', Chenggang Li ${ }^{2^{*}}$ D, Xiangshu Liu ${ }^{1}$ and Tao Zhang ${ }^{1}$
}

\begin{abstract}
Objective: The aim of this study is to investigate the effect of irisin on leukemia inhibitory factor (LIF) and integrin avß3 in implantation failure uterus.

Methods: Early pregnant rats were randomly divided into normal group (N), mifepristone treated group (M), irisin group (I) and progestin group (P). The implantation failure model was established using mifepristone. Second, we evaluated the average number of embryos and detected the expression of LIF and integrin av $\beta 3$ protein and mRNA in endometrium.
\end{abstract}

Results: Compared with group M, the average number of embryos was significantly higher in group N, P and I, the expression of LIF and integrin av $\beta 3$ in endometrium was significantly higher in group N, P and I.

Conclusion: Irisin could improve the poor receptive state of endometrium by promoting LIF and integrin av $\beta 3$ secretion to improve blastocyst implantation in rats of implantation failure.

Keywords: Irisin, Endometrium, Leukemia inhibitory factor, Integrin av $\beta 3$

\section{Background}

Irisin, a newly discovered myokine, is released from the muscle immediately after exercise. It is secreted from fibronectin type III domain containing 5 (FNDC5) after the cleavage of its extracellular protein [1]. It drives brown-fat-like conversion of white adipose tissues (WAT) and therefore has been suggested to improve metabolic and glucose homeostasis [2]. Since its discovery, irisin has been the subject of many studies due to its physiopathyological role. Irisin has initially been described as a protective factor against diet-induced weight gain, mediated by browning of WAT and thus increased energy expenditure [3]. Many subsequent studies have investigated a potential role in metabolic diseases, including obesity, type 2 diabetes mellitus (T2DM), nonalcoholic fatty liver disease (NAFLD), lipid metabolism

\footnotetext{
* Correspondence: litianle20160217@163.com

${ }^{2}$ Hubei Key Laboratory of Wudang Local Chinese Medicine Research, School of Pharmaceutical Sciences, Hubei University of Medicine, Shiyan, Hubei 442000, P.R. China

Full list of author information is available at the end of the article
}

and cardiovascular disease (CVD), polycystic ovary syndrome (PCOS), and metabolic bone diseases [4]. However, the reproductive effects of this hormone, if any, remain largely unexplored.

Reproductive capability is closely linked to the metabolism condition of the adipose tissue, both obesity and undernutrition have been found to be associated with reproductive dysfunction [5, 6]. Existing evidence of the role of biological factors, such as leptin, insulin and adiponectin, whose main function is to regulate energy metabolism, in reproduction is conclusive [7, 8]. Moreover, studies have shown that the expression of irisin has been identified in endometrium and ovary $[9,10]$. Based on these studies, we speculate that, irisin, a new molecular marker and target in metabolic disorder [11], may have potential effect on reproductive capacity. Due to the fact that receptive endometrium is the key for implantation at the early stage of successful pregnancy [12], the aim of this study was to investigate the effects of irisin on the expression of endometrial receptivity markers, including leukemia inhibitory factor (LIF) and integrin

(c) The Author(s). 2021 Open Access This article is licensed under a Creative Commons Attribution 4.0 International License, which permits use, sharing, adaptation, distribution and reproduction in any medium or format, as long as you give appropriate credit to the original author(s) and the source, provide a link to the Creative Commons licence, and indicate if changes were made. The images or other third party material in this article are included in the article's Creative Commons licence, unless indicated otherwise in a credit line to the material. If material is not included in the article's Creative Commons licence and your intended use is not permitted by statutory regulation or exceeds the permitted use, you will need to obtain permission directly from the copyright holder. To view a copy of this licence, visit http://creativecommons.org/licenses/by/4.0/ The Creative Commons Public Domain Dedication waiver (http://creativecommons.org/publicdomain/zero/1.0/) applies to the data made available in this article, unless otherwise stated in a credit line to the data. 
$\alpha v \beta 3$ at the implantation sites in implantation failure uterus.

\section{Materials and methods}

\section{Animals and grouping}

Sexually mature female wistar rats $(n=64)$, weight 210 $230 \mathrm{~g}$, and reproductive adult male wistar rats $(n=32)$, weight 250-300 g, SPF grade, were provided by the Medical Experimental Animal Center of Hubei Medical College. All rats were adaptively fed for 3 days. Observed the estrogen cycle of female rats, and rutting female rats were mated with male rats at $6 \mathrm{pm}$ and checked the viginal smear at $8 \mathrm{am}$ the next day. The first day of pregnancy (D1) was defined as sperm detection on the vaginal smear. Then randomly divided pregnant rats into normal group ( $\mathrm{N}, n=16)$ and implantation failure group $(n=48)$.

\section{Modeling and treatment}

The mifepristone tables (Qingdao Jie Shi Kang Biotechnology Co., Ltd. China) is dissolved in appropriate amount of edible sesame oil and the ultimate concentration was $2 \mathrm{mg} / \mathrm{ml}$. Rats in implantation failure group were treated with mifepristone solution at $5.5 \mathrm{mg} / \mathrm{kg}$ by neck subcutaneous injection on D1 at 9 am to establish the implantation failure model, while rats in group $\mathrm{N}$ were given an equal amount of sesame oil. Then randomly divided implantation failure rats into mifepristone treated group (group $\mathrm{M}, n=16$ ), irisin group (group I, $n=16$ ) and progestin group (group $\mathrm{P}, n=16$ ).

Then rats in group I and group P were respectively intramscularly injected with recombinant of irisin (Beijing Baiao Laibo Technology Co., Ltd. China; $100 \mathrm{ng} /$ g.d), and progestin (Zhejiang Xianju Pharmaceutical Co., Ltd., China; $40 \mathrm{mg} / \mathrm{kg} . \mathrm{d}$ ) from D1 to D6, while the group $\mathrm{M}$ and group $\mathrm{N}$ were injected with an equal volume of normal saline at the same time. Then rats in each group were equally randomized into 6-day pregnancy group and 10-day pregnancy group (respectively defined as N6 and N10, M6 and M10, I6 and I10, P6 and P10; $n=8$ for all groups). Rats in 6-day pregnancy group were sacrificed after injection on the 6th day of pregnancy, while rats in 10-day pregnancy group were raised to the 10th day of pregnancy and sacrificed.

\section{Tissue processing}

Rats were intraperitoneal narcotized with $2 \%$ pentobarbital sodium at $4 \mathrm{pm}$ on D6 and D10 for each group. The uteri were collected by laparotomy, the number of fetuses was counted for 10-day pregnant rats. The uteri of 6-day pregnant rats were scissored under anatomical lens. The endometria where the blastocysts attached to were collected, part of the endometrial were fixed in $4 \%$ paraformaldehyde, to be paraffin embedded, sliced; while others were stored at $-80^{\circ} \mathrm{C}$ for later use.

\section{Histological parameters}

Uterine tissues were fixed and sections of $5 \mu \mathrm{m}$ thickness were cut and stained with hematoxylin and eosin (HE) according to standard procedures. The morphology of endometrium was observed using Micro Image.

\section{Immunohistochemistry for LIF and integrin av $\beta 3$}

Paraffin sections were kept in oven at $60^{\circ} \mathrm{C}$ for $1 \mathrm{~h}$. Then these sections were deparaffinized and rehydrated through degraded ethanol. After that, antigen retrieval was performed by incubating these sections in $0.01 \mathrm{M}$ citrate buffer (PH 6.0) at $98^{\circ} \mathrm{C}$ for $20 \mathrm{~min}$. Then, endogenous hydrogen peroxidase activity was quenched using $3 \% \mathrm{H}_{2} \mathrm{O}_{2}$. Sections were blocked with $5 \%$ bovine serum albumin (BSA) for $30 \mathrm{~min}$. Excess BSA was drained. These sections were then incubated in respective primary antibody overnight at $4{ }^{\circ} \mathrm{C}$. Primary antibodies against LIF and integrin $\alpha v \beta 3$ were raised in rabbit (Boster Biological Technology Co., Ltd. China). For the negative control, slides were incubated in PBS. Then these sections were incubated with HRP labeled goat anti-rabbit IgG at $37^{\circ} \mathrm{C}$ for $1 \mathrm{~h}$ and incubated with substrate diaminobenzidine for 3-5 min and counterstained with Harris hematoxylin. Pictures were taken by a Nikon Micro-imaging system under 40 times light microscope, ten fields per slice, and analyzed with Image-Pro Plus 6.0 to measure average optical intensity (AOI).

\section{Elisa for LIF and integrin av $\beta 3$}

Uterus was chopped and homogenated, extracted total protein and detected protein content using BCA method. Samples were diluted to a concentration of 1$10 \mu \mathrm{g} / \mathrm{ml}$, then take $100 \mathrm{ul}$ of sample for Elisa. The procedure of quantitative sandwich enzyme immunoassay technique was followed according to the manufacturer's protocols (Cusabio Biological Technology Co., Ltd. China).

\section{Real-time PCR for LIF and integrin av $\beta 3$}

Uterus was dissociated with Trizol reagent (Takara Biotechnology Co., Ltd. China) and total RNA was extracted according to the manufacturer's protocols. RNA purity and concentration were measured using a nucleic acid/ protein analyzer. $1 \mu \mathrm{g}$ of extracted total RNA was reverse-transcribed with reverse transcription kit according to the manufacturer's protocols (Takara Biotechnology Co., Ltd. China) in Mastercycler gradient PCR apparatus. The primers were designed according to published sequences. Then $50 \mathrm{ul}$ of reaction system was performed for PCR amplification. Real-time PCR reactions 
were performed using an Applied Biosystems Step-One Real-Time PCR System, thermal cycler protocol: stage 1, Reps1 $95^{\circ} \mathrm{C} 30 \mathrm{~s}$; stage 2, Reps $4095^{\circ} \mathrm{C} 5 \mathrm{~s}, 60^{\circ} \mathrm{C} 30 \mathrm{~s}$; stage 3 , Reps $195^{\circ} \mathrm{C} 15 \mathrm{~s}, 60^{\circ} \mathrm{C} 1 \mathrm{~min}, 95^{\circ} \mathrm{C} 15 \mathrm{~s}$. The data were analyzed by the $2^{-\Delta \Delta \mathrm{CT}}$ method.

Primer sequences:

$\beta$-actin.

Forward primer: 5'-GGAGATTACTGCCCTGGC TCCTA-3'.

Reverse primer: 5'-GACTCATCGTACTCCTGC TTGCTG-3'.

LIF

Forward primer: 5'-ATCAAGAGTCAACTGGCT CAACTCA-3'.

Reverse primer: 5'- TGTTGGGCGCACATAGCT TAT-3'.

Integrin $\alpha v \beta 3$.

Forward primer: 5' -TTCAATGCCACCTGCCTCAA$3^{\prime}$.

Reverse primer: 5' -TGAAGCTCACCGTGTCTCCAA$3^{\prime}$.

\section{Statistical analysis}

Data were presented as the mean \pm standard deviation (SD). Statistical analysis was performed using SPSS 16.0 statistical software. Differences between any two groups were analyzed by independent t-test, and one-way analysis of variance (ANOVA) was used in a multigroup comparision, Chi-square test was used to compare qualitative data between groups. All $p$-values $<0.05$ were considered statistically significant.

\section{Results}

\section{Embryo implantation in rat uteri}

The uteri were examined for the number of implanted embryos and the morphological status. (Table 1, Figs. 1, 2).

Uterus in group $\mathrm{M}$ is pale, the distribution of implantation sites is asymmetric, the size of embryos is smaller and the uterine cavity is not closed. In contrast, uterus in group $\mathrm{N}$, group $\mathrm{P}$ and group I is bright red, the distribution of implantation sites is symmetric, the embryos is replete and the uterine cavity is closed.

Table 1 Pregnancy rate and average number of implanted embryos $( \pm S)$

\begin{tabular}{lll}
\hline Groups & Pregnancy rate & Average number of implanted embryos \\
\hline $\mathrm{N}(n=8)$ & $(7) 87.5 \%$ & $14.64 \pm 4.60$ \\
$\mathrm{M}(n=8)$ & $(2) 25 \%^{\mathrm{a}}$ & $2.71 \pm 1.25^{\mathrm{a}}$ \\
$\mathrm{I}(n=8)$ & $(7) 87.5^{\mathrm{b}}$ & $13.76 \pm 5.31^{\mathrm{b}}$ \\
$\mathrm{P}(n=8)$ & $(8) 100 \%^{\mathrm{b}}$ & $13.86 \pm 4.75^{\mathrm{b}}$
\end{tabular}

${ }^{a}$ represents that there is significant difference when group $M$ is compared with group $\mathrm{N}(P<0.05)$

${ }^{b}$ represents that there is significant difference when group I and $P$ is compared with group $\mathrm{M}(P<0.05)$
The average number of implanted embryos in group $\mathrm{M}$ is significantly decreased than that in group $\mathrm{N}(p=$ $0.01)$, however, the average number of embryos in group $\mathrm{I}$ and group $\mathrm{P}$ is obviously increased when compared with group $\mathrm{M}(p=0.002, p=0.001$, respectively). No significant differences were found in group $\mathrm{P}$, group $\mathrm{N}$ and group I $(p=0.931)$.

\section{Outcome of Elisa}

Endometrial LIF and integrin $\alpha \mathrm{v} \beta 3$ protein level on D6 is significantly lower in group $\mathrm{M}$ then that in group $\mathrm{N}$ (both $p<0.001$ ), while the level of LIF and integrin $\alpha \mathrm{v} \beta 3$ protein in group I and group P is obviously increased when compared with group $\mathrm{M}$ ( $p<0.001$ for both). No significant differences were found in group $\mathrm{P}$, group $\mathrm{N}$ and group I (LIF: $p=0.144$; integrin $\alpha v \beta 3: p=0.229$ ). (Table 2).

\section{Outcome of immunohistochemistry}

As is shown in Fig. 3, endometrial LIF protein is mainly expressed in mesenchymal cells, while integrin $\alpha v \beta 3$ protein is mainly expressed in luminal and glandular epithelium. The AOI of LIF and integrin $\alpha v \beta 3$ in group $M$ is significantly decreased then that in group $\mathrm{N}$ (both $p<$ 0.001 ); when compared with group $\mathrm{M}$, the AOI of LIF and integrin $\alpha v \beta 3$ is obviously increased in group I and group $\mathrm{P}(p<0.001$ for both $)$. No significant differences were found in group P, group $\mathrm{N}$ and group I (LIF: $p=$ 0.090; integrin $\alpha v \beta 3: p=0.297$ ). (Table 3, Fig. 3).

\section{Outcome of RT-PCR}

Compared with group $\mathrm{N}$, endometrial LIF and integrin $\alpha v \beta 3$ mRNA is significantly decreased in group $M$ (both $p<0.001$ ); while compared with group $\mathrm{M}$, there is a significantly elevation of the expression of LIF and integrin $\alpha v \beta 3$ mRNA in group I and group $\mathrm{P}(p<0.001$ for both). No significant differences were found in group $\mathrm{P}$, group $\mathrm{N}$ and group I (LIF: $p=0.090$; integrin $\alpha \mathrm{v} \beta 3: p=0.297$ ). (Table 4).

\section{Discussion}

Implantation is one of the most essential processes in reproduction and is the key for successful pregnancy. In this process, both energetic blastocyst and receptive endometrium are two prerequisites for successful implantation. Endometrial receptivity refers to a state that endometrial epithelial cells are structurally and functionally prepared for embryo implantation. A number of molecules have been recognized as markers of endometrial receptivity, including ovarian hormones and their receptors, integrin $\alpha v \beta 3$, LIF and so on.

It's known that mifepristone is a classical antagonist to progesterone which specifically blocks the action of progesterone and resists implantation [13]. These well- 


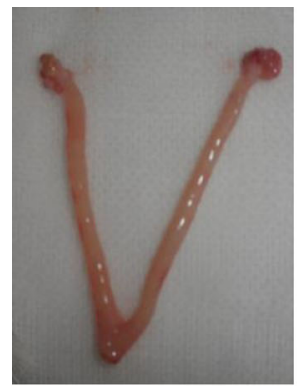

N6

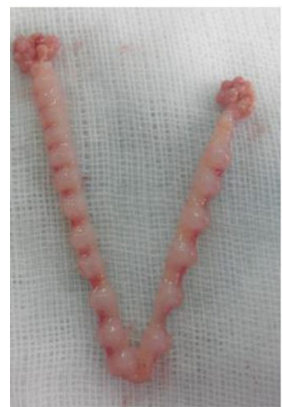

N10

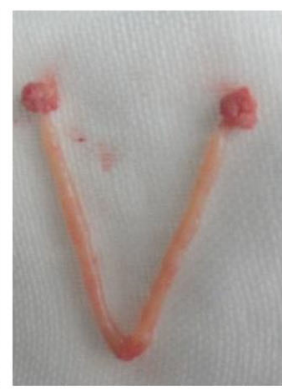

M6

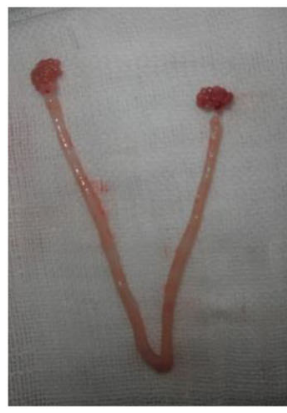

M10

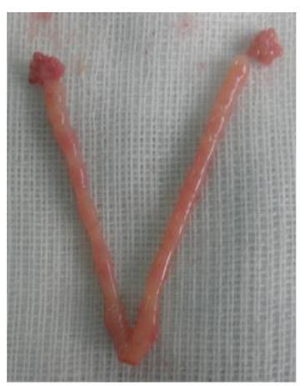

16

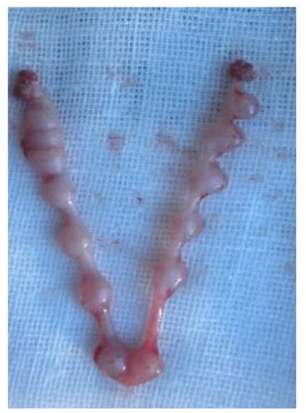

110

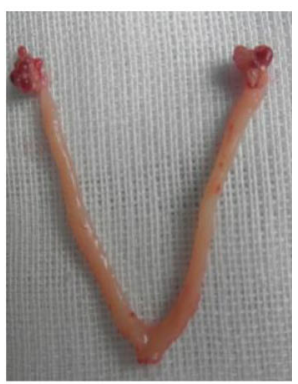

P6

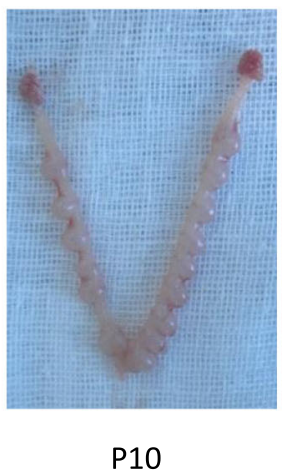

N6: Uterus of group N on D6; N10: Uterus of group N on D10;

M6: Uterus of group M on D6; M10: Uterus of group M on D10;

16: Uterus of group I on D6; I10: Uterus of group I on D10;

P6: Uterus of group P on D6; P10: Uterus of group P on D10.

Fig. 1 Appearance of rat uterus

known endometrial receptivity markers, such as LIF, integrin $\alpha v \beta 3$, have the same characteristic, that is, they can all be regulated by progesterone directly or indirectly [14]. Therefore, mifepristone can destroy the endometrial receptivity and inhibit blastocyst implantation. Yet in our study, mifepristone significantly reduced the number of implantation blastocysts and lead to a decrease in endometrial LIF and integrin $\alpha v \beta 3$ levels, this suggests that we have successfully used mifepristone to establish the implantation failure model, which provides a basis for the futher observation of the function of irisin on the endometrium.

Irisin has gained a marked insight in the field of medical biology and its potential therapeutic importance in metabolic diseases. Even though, it is important to explore the role of irisin in other pathological/physiological conditions.

Studies demonstrated that the expression of irisin has been found in endometrium and endometrial irisin level in PCOS patients decreased $[9,10]$, which indicated a potential direct role of irisin on endometrium. Embryo implantation is the premise of successful pregnancy, it is crucial to take timely modifications for endometrium to become receptive to the developing embryo for success of implantation [12]. As a result, observing the effect of irisin on endometrial receptivity is of great significance for explore its reproductive effects.

The present study demonstrated that the average number of implantation blastocysts was notably increased in irisin group than mifepristone group, and irisin can improve the reduction of LIF and integrin $\alpha v \beta 3$ caused by mifepristone, which confirmed a potential function of irisin on endometrial receptivity. To our knowledge, few studies have reported on the effect of irisin on endometrial function. Our novel finding provides significant information for exploring the reproductive role of Irisin, at the same time provides a new target for the diagnosis and treatment of infertility. However, no exact evidence is available on the possible molecular mechanism of this role in endometrium. Possible 


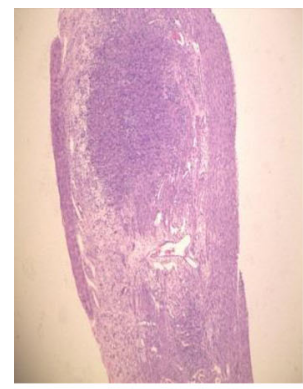

N6

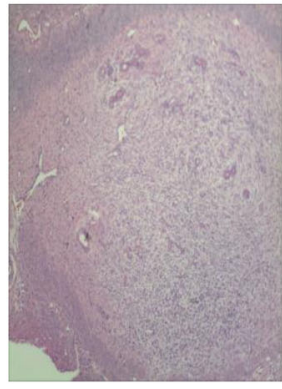

N10

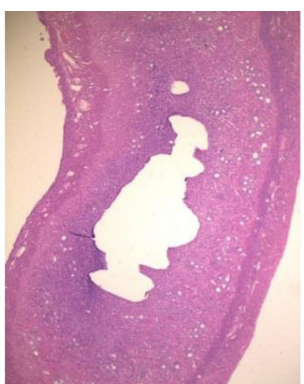

M6

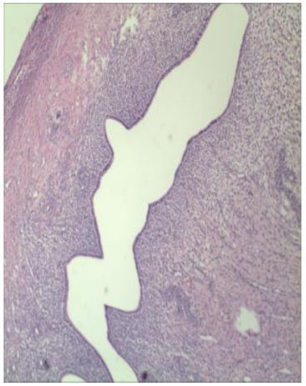

M10

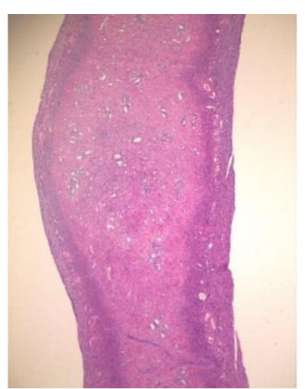

16

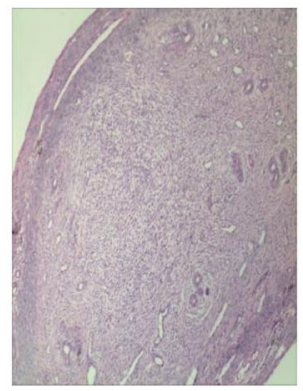

110

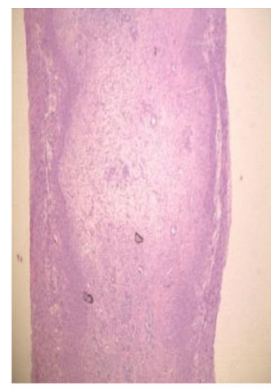

P6

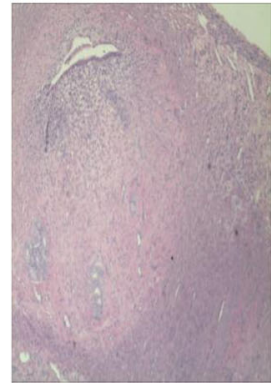

P10

N6: Uterus of group N on D6; N10: Uterus of group N on D10;

M6: Uterus of group M on D6; M10: Uterus of group M on D10;

16: Uterus of group I on D6; I10: Uterus of group I on D10;

P6: Uterus of group P on D6; P10: Uterus of group P on D10.

Fig. 2 Morphological changes observed under light microscope (Original magnification: $\times 40$ )

explanation of the present study on potential pathways is that irisin regulate energy metabolism in the body and uterus.

Reproductive and fertility are closely linked to energy metabolism and the endocrine function of the adipose tissue [5,6]. Moderate physical activity is beneficial for reproductive function [15]. Studies have highlighted the endometrium's role in the pathophysiology of adverse reproductive outcomes among obese women [16-18].

Table 2 Comparison of endometrium cytokines protein concentration by Elisa. $( \pm S)$

\begin{tabular}{lll}
\hline Groups $(\boldsymbol{n}=\mathbf{8})$ & LIF $(\mathbf{p g} / \mathbf{m l})$ & integrin $\mathbf{a v} \boldsymbol{\beta} \mathbf{3}(\mathbf{p g} / \mathbf{m l})$ \\
\hline $\mathrm{N}$ & $72.96 \pm 8.13$ & $83.98 \pm 7.62$ \\
$\mathrm{M}$ & $20.14 \pm 2.88^{\mathrm{a}}$ & $36.61 \pm 5.47^{\mathrm{a}}$ \\
$\mathrm{I}$ & $66.87 \pm 6.89^{\mathrm{b}}$ & $87.32 \pm 8.98^{\mathrm{b}}$ \\
$\mathrm{P}$ & $71.47 \pm 7.73^{\mathrm{b}}$ & $79.14 \pm 6.38^{\mathrm{b}}$ \\
\hline
\end{tabular}

arepresents that there is significant difference when group $M$ is compared with group $\mathrm{N}(P<0.001)$

${ }^{b}$ represents that there is significant difference when group I and $P$ is compared with group $M(P<0.001)$
To be more specific, Bellver et al. published a clinical study of 9587 first cycles of ovum donation and showed that implantation, pregnancy, and live birth were significantly reduced as BMI (body mass index) increased, it was suggested that female obesity impairs the reproductive outcome of ovum donation probably as a result of reduced receptivity [19]. Bellver et al. also published a review supporting a role for endometrium in the pathophysiology of reproduction in obese women [20]. Moreover, it has been reported that obesity and exposure to a high-fat diet impair endometrial stromal cell decidualization, which is necessary for uterine receptivity [21]. In addition, studies have highlighted that high concentration of insulin could inhibit expression of endometrial receptivity markers such as integrins, osteopontin [22, 23]. It's believed that, efficient nutrients exchange between the uteri and fetus, including glycogen, proteins and lipids, is essential for a successful pregnancy [24]. During the early stage of implantation, the embryo is nourished via nutritive endometrial secretions, which derived from endometrial glands, and the secretions play an important role in regulating endometrial receptivity 


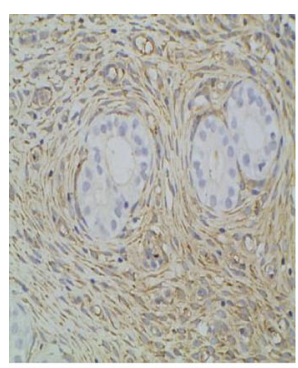

$\mathrm{N}$

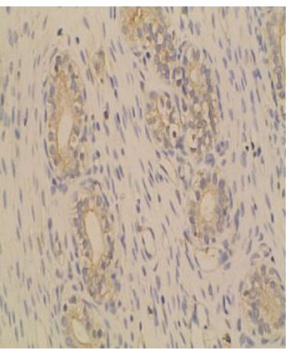

N

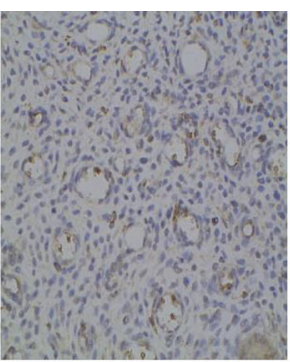

M

a: expression of LIF

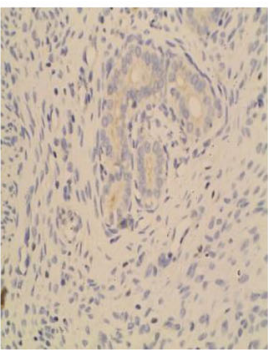

M

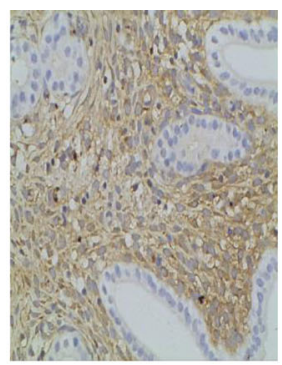

I

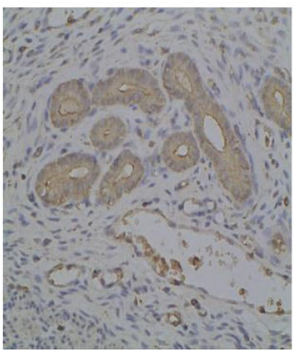

I

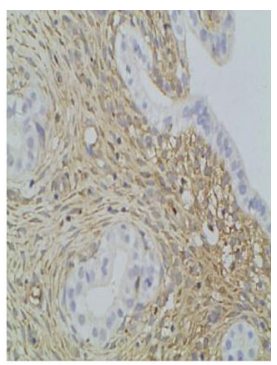

$P$

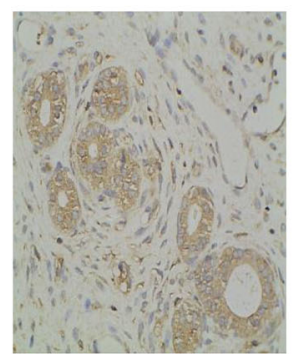

$P$

$b$ : expression of integrin $\alpha v \beta 3$

Fig. 3 Immunohistochemical staining (Original magnification: $\times$ 400)

[24-26]. In addition, hormones whose main function is to regulate energy metabolism, such as leptin, is involved in reproductive function and, more precisely, in the embryonic-maternal cross-talk at the time of implantation [27]. Based on these studies, it is reasonable to speculate that, irisin, a hormone whose main function is to regulate energy metabolism and improve insulin resistance, may play a crucial role in endometrial receptivity by regulating systemic metabolism and local nutritional metabolism of the uterus. Our study indicates that irisin may play a major role in metabolic diseases complicated with infertility, such as obesity and PCOS, it can improve endometrial receptivity while regulating metabolic abnormalities, which is superior to progesterone only to improve the

Table 3 Comparison of endometrium cytokines protein average optical intensity by immunohistochemistry. $( \pm S)$

\begin{tabular}{lll}
\hline Groups $(\boldsymbol{n}=8)$ & \multicolumn{2}{l}{ Average optical density } \\
\cline { 2 - 3 } & LIF & integrin $\operatorname{av} \boldsymbol{\beta 3}$ \\
\hline $\mathrm{N}$ & $0.42 \pm 0.09$ & $0.47 \pm 0.12$ \\
$\mathrm{M}$ & $0.13 \pm 0.05^{\mathrm{a}}$ & $0.16 \pm 0.05^{\mathrm{a}}$ \\
$\mathrm{I}$ & $0.36 \pm 0.07^{\mathrm{b}}$ & $0.41 \pm 0.11^{\mathrm{b}}$ \\
P & $0.43 \pm 0.11^{\mathrm{b}}$ & $0.39 \pm 0.12^{\mathrm{b}}$
\end{tabular}

${ }^{a}$ represents that there is significant difference when group $M$ is compared with group $\mathrm{N}(P<0.001)$

${ }^{b}$ represents that there is significant difference when group I and $P$ is compared with group $M(P<0.001)$ function of the endometrium. Our study provides a new perspective for the treatment of obesity, PCOS patients complicated with infertility.

In addition, physical activity has been proposed to provide benefits in women attempting pregnancy, especially those with higher BMI, but the specific mechanism is confusing [15]. since irisin increases energy metabolism and improves the function of the endometrium, we can make a bold hypothesis, that is, physical activity can effectively improve the body's metabolism and reproductive disorders after increasing the release of irisin. This may provides a scientific basis for women to improve reproductive function through physical activity especially those with higher BMI.

Table 4 Comparison of endometrium cytokines mRNA concentration by RT-PCR $( \pm S)$

\begin{tabular}{lll}
\hline Groups $(\boldsymbol{n}=8)$ & LIF & integrin $\operatorname{av\beta 33}$ \\
\hline $\mathrm{N}$ & $0.93 \pm 0.24$ & $0.78 \pm 0.22$ \\
$\mathrm{M}$ & $0.37 \pm 0.10^{\mathrm{a}}$ & $0.31 \pm 0.10^{\mathrm{a}}$ \\
$\mathrm{I}$ & $0.86 \pm 0.21^{\mathrm{b}}$ & $0.73 \pm 0.22^{\mathrm{b}}$ \\
$\mathrm{P}$ & $0.89 \pm 0.17^{\mathrm{b}}$ & $0.81 \pm 0.19^{\mathrm{b}}$ \\
\hline
\end{tabular}

arepresents that there is significant difference when group $M$ is compared with group $\mathrm{N}(P<0.001)$

${ }^{b}$ represents that there is significant difference when group I and $P$ is compared with group $M(P<0.001)$ 


\section{Conclusions}

The present study demonstrated that irisin could improve the poor receptive state in implantation failure uterus by promoting LIF and integrin $\alpha \mathrm{v} \beta 3$ secretion to improve blastocyst implantation. Future studies to confirm our initial observations and to explore the possible pathways are warranted.

\section{Acknowledgements}

None.

\section{Authors' contributions}

Chenggang Li and Li Zhou conceived, designed and performed the majority of the experiments and drafted the manuscript. Li Zhou and Xiangshu Liu provided valuable discussion and modified the final manuscript. Tao Zhang participated in experimental procedures and data analysis. All authors read and approved the final manuscript.

\section{Funding}

The research was supported by Hubei Provincial Education Department Research Fund (B2018437) and Shiyan City Research Fund (18Y08,19Y94).

\section{Availability of data and materials}

The datasets used and analyzed during the current study are available from the corresponding author on reasonable request.

\section{Ethics approval and consent to participate}

The Animal Research Ethics Committee of Hubei Medical College approved the study protocol (Approval No.2018-87). We state that the "Principles of Laboratory Animal Care" (NIH publication No. 86-23, revised 1985) were followed as well as specific national laws where applicable.

\section{Competing interests}

The authors declare that no competing financial.

\section{Author details}

'Department of Traditional Chinese Medicine, Affliated Dongfeng Hospital, Hubei University of Medicine, Shiyan, Hubei 442000, P.R. China. ${ }^{2}$ Hubei Key Laboratory of Wudang Local Chinese Medicine Research, School of Pharmaceutical Sciences, Hubei University of Medicine, Shiyan, Hubei 442000, P.R. China.

Received: 26 December 2019 Accepted: 28 January 2021

Published online: 03 February 2021

\section{References}

1. Panati K, Suneetha Y, Narala VR. Irisin/FNDC5--an updated review. Eur Rev Med Pharmacol Sci. 2016;20:689-97.

2. Shi X, Lin M, Liu C, et al. Elevated circulating irisin is associated with lower risk of insulin resistance: association and path analyses of obese Chinese adults. BMC Endocr Disord. 2016;16:44.

3. Bostrom P, WU J, Jedrychowski MP, et al. A PGC1- alpha-dependent myokine that drives brown-fat-like development of white fat and thermogenesis. Nature. 2012;481:463-8.

4. Polyzos SA, Anastasilakis AD, Efstathiadou ZA, et al. Irisin in metabolic diseases. Endocrine. 2018:59:260-74.

5. Pasquali R, Patton L, Gambineri A. Obesity and infertility. Curr Opin Endocrinol Diabetes Obes. 2007;14:482-7.

6. Abecia JA, Sosa C, Forcada F, et al. The effect of undernutrition on the establishment of pregnancy in the ewe. Reprod Nutr Dev. 2006;46:367-78.

7. Mathew H, Castracane VD, Mantzoros C. Adipose tissue and reproductive health. Metabolism. 2018;86:18-32.

8. Kawwass JF, Summer R, Kallen CB. Direct effects of leptin and adiponectin on peripheral reproductive tissues: a critical review. Mol Hum Reprod. 2015; 21:617-32.

9. Gür FM, Timurkaan S, Yalcin MH, et al. Immunohistochemical localization of irisin in mole rats (Spalax leucodon). Biotech Histochem. 2017;92:245-51.

10. Guo Y. Correlation between irisin in serum and endometrium and polycystic ovary syndrome. Shijiazhuang: Hebei Medical University; 2016.
11. Chen JQ, Huang YY, Gusdon AM, et al. Irisin:a new molecular marker and target in metabolic disorder. Lipids Health Dis. 2015;14:2.

12. Kim SM, Kim JS. A review of mechanisms of implantation. Dev Reprod. 2017; 21:351-9.

13. Shang SL. The clinical application of mifepristone in the birth control. Med Recapitulate. 2006;12:1011-3.

14. Sun X, Qiu X, Gemzell-Danielsson K. Effects of mifepristone on expression of endothelial nitric oxide synthase in human endometrium during the implantation phase. Fertil Steril. 2003;80:1454-60.

15. Russo LM, Whitcomb BW, Mumford SL, et al. A prospective study of physical activity and fecundability in women with a history of pregnancy loss. Hum Reprod. 2018;33:1291-8.

16. Deugarte DA, DeUgarte CM, Sahakian V. Surrogate obesity negatively impacts pregnancy rates in third-party reproduction. Fertil Steril. 2010;93: 1008-10.

17. Dessolle L, Darai $E$, Cornet $D$, et al. Determinants of pregnancy rate in the donor oocyte model: a multivariate analysis of 450 frozen-thawed embryo transfers. Hum Reprod. 2009;24:3082-9.

18. Bellver J, Ayllon $Y$, Ferrando $M$, et al. Female obesity impairs in vitro fertilization outcome without affecting embryo quality. Fertil Steril. 2010;93: 447-54.

19. Bellver J, Pellicer A, Garcia-Velasco JA, et al. Obesity reduces uterine receptivity: clinical experience from 9587 first cycles of ovum donation with normal weight donors. Fertil Steril. 2013:100:1050-8.

20. Bellver J, Martinez-Conejero JA, Labarta E, et al. Endometrial gene expression in the window of implantation is altered in obese women especially in association with polycystic ovary syndrome. Fertil Steril. 2011; 95:2335-541.

21. Rhee JS, Saben $J \mathrm{~L}$, Mayer $A L$, et al. Diet-induced obesity impairs endometrial stromal cell decidualization: a potential role for impaired autophagy. Hum Reprod. 2016;31:1315-26.

22. Wang CY, CFi D. Research progress of insulin resistance and endometrial receptivity in patients with polycystic ovary syndrome. Zhejiang Integr Med. 2012;22:155-8.

23. Sun $\mathrm{XL}$. Effect of insulin resistance on reproductive function in patients with polycystic ovary syndrome. Shanghai: Fudan University; 2013.

24. Burtona GJ, Sciosciab M, Rademacherc TW. Endometrial secretions: creating a stimulatory microenvironment within the human early placenta and implications for the aetiopathogenesis of preeclampsia. J Reprod Immunol. 2011;89:118-25

25. Burton GJ, Jauniaux E, Charnock-Jones DS. Human early placental development: potential roles of the endometrial glands. Placenta. 2007;28: S64-9.

26. Kelleher AM, Milano-Foster J, Behura SK, et al. Uterine glands coordinate ontime embryo implantation and impact endometrial decidualization for pregnancy success. Nat Commun. 2018;22:2435.

27. Yang YJ, Cao YJ, Bo SM, et al. Leptin-directed embryo implantation: Leptin regulates adhesion and outgrowth of mouse blastocysts and receptivity of endometrial epithelial cells. Anim Reprod Sci. 2006;92:155-67.

\section{Publisher's Note}

Springer Nature remains neutral with regard to jurisdictional claims in published maps and institutional affiliations.

Ready to submit your research? Choose BMC and benefit from:

- fast, convenient online submission

- thorough peer review by experienced researchers in your field

- rapid publication on acceptance

- support for research data, including large and complex data types

- gold Open Access which fosters wider collaboration and increased citations

- maximum visibility for your research: over $100 \mathrm{M}$ website views per year

At $\mathrm{BMC}$, research is always in progress.

Learn more biomedcentral.com/submissions 